\title{
Article \\ Clinical Outcome of Rotational Atherectomy in Calcified Lesions in Korea-ROCK Registry
}

\author{
Kyusup Lee ${ }^{1}{ }^{\oplus}$, Ji-hoon Jung ${ }^{2}$, Myunhee Lee ${ }^{1} \oplus$, Dae-Won Kim ${ }^{1}$, Mahn-Won Park ${ }^{1}$, Ik-Jun Choi ${ }^{3} \oplus$, \\ Jae-Hwan Lee ${ }^{4}$, Jang-Hoon Lee ${ }^{5}{ }^{(0}$, Sang-Rok Lee ${ }^{6}{ }^{(0)}$, Pil-Hyung Lee ${ }^{7}$, Seung-Whan Lee ${ }^{7}$, Ki-Dong Yoo ${ }^{8}$, \\ Kyeong-Ho Yun ${ }^{9}$, Hyun-Jong Lee ${ }^{10}$ and Sung-Ho Her ${ }^{8, *(1)}$
}

1 Department of Cardiology, Daejeon St. Mary's Hospital, College of Medicine, The Catholic University of Korea, Seoul 06591, Korea; ajobijh@hanmail.net (K.L.); myunheelee@catholic.ac.kr (M.L.); mirinesilver@catholic.ac.kr (D.-W.K.); pmw6193@catholic.ac.kr (M.-W.P.)

2 Korea Institute of Toxicology, Daejeon 34114, Korea; jihoon.jung@kitox.re.kr

3 Department of Cardiology, Incheon St. Mary's Hospital, College of Medicine, The Catholic University of Korea, Incheon 21431, Korea; mrfasthand@catholic.ac.kr

4 Department of Cardiology in Internal Medicine, Chungnam National University Hospital, Daejeon 35015, Korea; myheart@cnuh.co.kr

5 Department of Internal Medicine, Kyungpook National University Hospital, Daegu 41944, Korea; ljhmh75@knu.ac.kr

6 Department of Cardiology, Chonbuk National University Hospital, Jeonju 54907, Korea; medorche@naver.com

7 Asan Medical Center, Department of Cardiology, University of Ulsan College of Medicine, Seoul 05505, Korea; pilmo11@hanmail.net (P.-H.L.); seungwlee@amc.seoul.kr (S.-W.L.)

8 Department of Cardiology, St. Vincent's Hospital, College of Medicine, The Catholic University of Korea, Seoul 06591, Korea; yookd@catholic.ac.kr

check for updates

Citation: Lee, K.; Jung, J.-h.; Lee, M.; Kim, D.-W.; Park, M.-W.; Choi, I.-J.; Lee, J.-H.; Lee, J.-H.; Lee, S.-R.; Lee, P.-H.; et al. Clinical Outcome of Rotational Atherectomy in Calcified Lesions in Korea-ROCK Registry. Medicina 2021, 57, 694. https:/ / doi.org/10.3390/medicina57070694

Academic Editor: Tomasz Zieliński

Received: 19 May 2021

Accepted: 5 July 2021

Published: 7 July 2021

Publisher's Note: MDPI stays neutral with regard to jurisdictional claims in published maps and institutional affiliations.

Copyright: (c) 2021 by the authors. Licensee MDPI, Basel, Switzerland. This article is an open access article distributed under the terms and conditions of the Creative Commons Attribution (CC BY) license (https:/ / creativecommons.org/licenses/by/ $4.0 /)$.
9 Regional Cardiocerebrovascular Center, Department of Cardiovascular Medicine, Wonkwang University Hospital, Iksan 54538, Korea; ards7210@wonkwang.ac.kr

10 Department of Internal Medicine, Sejong General Hospital, Bucheon 14754, Korea; untouchables00@hanmil.net

* Correspondence: hhhsungho@naver.com; Tel.: +82-10-7731-0052

Abstract: Background and Objectives: Data is still limited regarding clinical outcomes of rotational atherectomy (RA) after percutaneous coronary intervention. We sought to evaluate clinical outcomes of RA. Materials and Methods: This multi-center registry enrolled patients who underwent RA during PCI from nine tertiary centers in Korea between January 2010 and October 2019. The primary endpoint was target-vessel failure (TVF; the composite outcome of cardiac death, target-vessel spontaneous myocardial infarction, or target-vessel revascularization). Results: Of 540 patients (583 lesions), the mean patient age was $71.4 \pm 0.4$ years, 323 patients $(59.8 \%)$ were men, and 305 patients $(56.5 \%)$ had diabetes mellitus. Technical success rate was $96.4 \%$. In-hospital major adverse cerebral and cardiac events occurred in 63 cases (10.8\%). At 1.5 years, $72(16.0 \%)$ of TVFs were occurred. We evaluated independent predictors of TVF, which included current smoker (hazard ratio (HR), 1.92; $95 \%$ confidence interval $(\mathrm{CI}), 1.17-3.16 ; p=0.01)$, chronic renal disease $(\mathrm{HR}, 1.87 ; 95 \% \mathrm{CI}, 1.14-3.08$; $p=0.013)$, history of cerebrovascular attack (HR, 2.14; 95\% CI, 1.24-3.68; $p=0.006)$, left ventricle ejection fraction (HR, 0.98; 95\% CI, 0.97-0.999; $p=0.037)$, and left main disease (HR, 1.94; 95\% CI, 1.11-3.37; $p=0.019)$. Conclusions: From this registry, we demonstrated acceptable success rates, in-hospital and mid-term clinical outcomes of RA in the DES era.

Keywords: percutaneous coronary intervention; rotational atherectomy; drug-eluting stent; clinical outcome

\section{Introduction}

With the development of device technology, there have been expanded indications of percutaneous coronary intervention (PCI) to more challenging cases. Moreover, as the 
elderly population increases, we can get a more chance to meet patients with complex calcified coronary lesions in clinical practice [1].

With this current change, methods for modifying calcified coronary lesions have been more and more important (such as a non-compliant balloon, cutting/scoring balloon, orbital atherectomy, intravascular lithotripsy, and rotational atherectomy (RA)) [2-5]. The RA system is composed of a high-speed rotating diamond-coated burr that modifies calcified lesions. Therefore, it is a useful device for plaque modification of those lesions to facilitate balloon and stent delivery [6,7]. However, in our daily practice, patients qualified for RA are often "non-option" patients due to their comorbidity. Operators should be concerned about procedure-related complications and adverse clinical outcomes [8-12]. With the widespread use of second-generation drug-eluting stents (DES), optimal medical treatment, including statin and intravascular image, there has been a need for updated clinical results of RA in real-world practice. Therefore, we designed this study to introduce our registry and to investigate procedural outcomes, in-hospital events, and clinical outcomes of RA in the DES era.

\section{Materials and Methods}

\subsection{Study Design and Population}

The study population consisted of 540 patients (583 lesions) with calcified coronary artery disease (CAD) who underwent PCI using RA between January 2010 and October 2019 at 9 tertiary centers, from the 'ROtational atherectomy in Calcified lesions in Korea (ROCK)' registry. Data were collected at each site using a standardized case report form to record demographic and clinical characteristics and procedural and follow-up data. Follow-up data were collected retrospectively, based on medical records and a physician or patient interview. The local ethics committee approved this study of each hospital.

Between 2010 and 2019, consecutive patients with heavily calcific coronary lesions and significant stenosis (stenosis $\geq 70 \%$ of vessel diameter) who underwent PCI using RA were retrospectively enrolled from each institutional database. After reviewing angiography, two lesions could not be performed RA were dropped out from the registry. One experienced coronary perforation and cardiac tamponade before the RA procedure. The other could not pass the wire through the target lesion. Chronic kidney disease (CKD) was defined as an estimated glomerular filtration rate $<60 \mathrm{~mL} / \mathrm{min} / 1.73 \mathrm{~m}^{2}$, as calculated using the Modification of Renal Diet equation from baseline serum creatinine [13].

\subsection{Procedure}

The treatment strategy, including decisions of performing/timing of RA, burr size, and selection of vascular access, was at the discretion of the attending cardiologists with careful consideration of clinical risk factors, anatomical complexity, patients' conditions. Standard techniques and management guided all procedures. All RA procedures were performed using the Rotablator ${ }^{\mathrm{TM}}$ RA system (Boston Scientific, Marlborough, MA, USA). During RA, pauses in ablation runs and intracoronary nitroglycerin and/or verapamil were used to avoid coronary spasm and slow flow phenomenon. Antiplatelet therapy and peri-procedural anticoagulation were performed following the accepted guidelines [14,15].

\subsection{Study Outcomes}

The primary endpoint of the study was the occurrence of target-vessel failure (TVF), defined as cardiac death, target-vessel spontaneous myocardial infarction (MI), or target vessel revascularization (TVR). The secondary endpoint was all-cause death, cardiac death, any MI, target-vessel spontaneous MI, any repeat revascularization (RR), TVR, target-lesion revascularization (TLR), stent thrombosis (ST), coronary artery bypass grafting (CABG) surgery, cerebrovascular accident (CVA), and bleeding.

Technical success was defined as the achievement of residual stenosis $<30 \%$ in the presence of grade III Thrombolysis in myocardial infarction flow. Procedural success was defined as achieving technical success without in-hospital major adverse cerebral and 
cardiac events (MACCEs), including in-hospital death, in-hospital CVA, urgent revascularization (CABG or PCI), peri-procedural MI or ST during the index hospitalization period. Procedural complications included cardiac tamponade, coronary perforation, severe coronary dissection, defined from The National Heart, Lung, and Blood Institute classification system as type D, E, and F, temporary pacemaker insertion, contrast-induced nephropathy, or in-hospital bleeding.

We investigated procedure time, radiation dose, and contrast amount to assess procedural efficiency and safety. We also reviewed contrast-induced nephropathy (CIN) after $\mathrm{PCI}$, which was defined as the impairment of kidney function-measured as either a $25 \%$ increase in serum creatinine from baseline or a $0.5 \mathrm{mg} / \mathrm{dL}$ increase in absolute serum creatinine value within $48-72 \mathrm{~h}$ after the procedure.

Death was defined as death from any cause. Target-vessel spontaneous MI was spontaneous MI clearly attributable to the target vessel. Spontaneous MI was defined as any creatine kinase-myocardial band or troponin increase above the upper limit of the normal range with ischemic symptoms or signs during follow-up after discharge. Periprocedural MI was defined as peak elevations of the creatine kinase-myocardial band of $>10$-fold above the upper reference limit within $48 \mathrm{~h}$ after the procedure [16]. RR was defined as any percutaneous or surgical revascularization in any vessel. TVR was defined as any percutaneous or surgical revascularization of the treated vessel. TLR was defined as any percutaneous or surgical revascularization of the treated lesion. CVA was defined as a focal neurological deficit of central origin lasting $>24 \mathrm{~h}$, confirmed by a neurologist and imaging. All clinical events were confirmed by source documentation collected at each hospital and centrally adjudicated by an independent group of clinicians unaware of the revascularization type.

\subsection{Statistical Analyses}

Continuous variables were presented as mean \pm standard deviation (SD) and compared using the Student $t$-test or Mann-Whitney $U$ test. Categorical variables were presented as counts (percentages) and compared using the chi-square or Fisher exact test, as appropriate. Event rates were estimated on Kaplan-Meier estimates in time-to-first-event analyses, and they were compared using the log-rank test. A univariate Cox regression analysis was performed to obtain the hazard ratio (HR) for clinical outcomes. Then, to find out the independent predictors with the clinical outcomes, a multivariate Cox proportional hazard regression model was performed using important clinical covariates including clinically relevant variables and statistically significant variables with a $p$-value $<0.1$ by univariate analysis. All reported $\mathrm{p}$ values were two-sided, and $p$ values $<0.05$ were considered statistically significant. Statistical analysis was performed with Statistical Package for Social Sciences, version 18.0.0 (SPSS Inc., Chicago, IL, USA).

\section{Results}

\subsection{Baseline Patient, Lesion, and Procedural Characteristics}

From January 2010 to October 2019, a total of 540 patients (583 lesions) who received PCI using RA were enrolled (Figure 1). Baseline patient characteristics are summarized in Table 1. The mean age was $71.4 \pm 0.4$ years (range, 19-104 years), and $323(59.8 \%)$ patients were male gender. Three hundred five (56.5\%) patients had diabetes mellitus. More than $60 \%$ of patients were diagnosed with the acute coronary syndrome. The mean left ventricular ejection fraction was $53.0 \pm 13.4$. Dual antiplatelet therapy (DAPT) and statin were prescribed well at discharge (95.9\% and $92.4 \%$, respectively). 
Table 1. Baseline characteristics of the patients.

\begin{tabular}{cc}
\hline Characteristics & Mean \pm SD, $\mathbf{n}(\mathbf{\%})$ or Median (IQR) (n = 540) \\
\hline Age (years) & $71.4 \pm 0.4$ \\
Male & $323(59.8)$ \\
BMI $\left(\mathrm{kg} / \mathrm{m}^{2}\right)$ & $24.2 \pm 3.9$ \\
Diabetes mellitus & $305(56.5)$ \\
Insulin use & $72(13.3)$ \\
Hypertension & $415(76.9)$ \\
Hyperlipidemia & $235(43.5)$ \\
Current smoker & $103(19.1)$ \\
Clinical presentation & \\
Silent ischemia & $37(6.9)$ \\
Stable angina & $176(32.6)$ \\
Unstable angina & $175(32.4)$ \\
NSTEMI & $133(24.6)$ \\
STEMI & $19(3.5)$ \\
Presented as ACS & $327(60.6)$ \\
Chronic kidney disease & $96(17.8)$ \\
Prior MI & $66(12.2)$ \\
Prior PCI & $138(25.6)$ \\
Prior CABG & $24(4.4)$ \\
Peripheral vascular disease & $39(7.2)$ \\
History of heart failure & $77(14.3)$ \\
Atrial fibrillation & $49(9.1)$ \\
LV EF, $\%$ & $53.0 \pm 13.4$ \\
Aspirin & \\
Pedication at discharge & $529(98.0)$ \\
DAPT & $530(98.1)$ \\
B-blocker & $518(95.9)$ \\
ACEI/ARB & $381(70.6)$ \\
Statin & $341(63.1)$ \\
NOAC & $499(92.4)$ \\
& $17(2.9)$ \\
\hline
\end{tabular}

Values are presented as $\mathrm{n}(\%)$ or mean $\pm \mathrm{SD}$. Abbreviations: SD, standard deviation; IQR, interquartile range; $\mathrm{BMI}$, body mass index; CAD, coronary artery disease; NSTEMI, non-ST elevation myocardial infarction; STEMI, ST-elevation myocardial infarction; ACS, acute coronary syndrome; MI, myocardial infarction; PCI, percutaneous coronary intervention; $\mathrm{CABG}$, coronary artery bypass grafting; $\mathrm{LV} E \mathrm{EF}$, left ventricle ejection fraction; DAPT, dual antiplatelet therapy; ACEI/ARB, angiotensin-converting-enzyme inhibitor/angiotensin II receptor blocker; NOAC, non-vitamin $\mathrm{K}$ oral anticoagulant.

The majority of lesions were classified as type B2 $(10.1 \%)$ or $\mathrm{C}(82.3 \%)$ according to the American College of Cardiology and the American Heart Association (ACC/AHA) classification. Left anterior descending (LAD), including left main (LM), left circumflex (LCX) coronary artery, and right coronary artery (RCA) was involved in $65.9 \%, 10.1 \%$, and $24.0 \%$, respectively. LM and multivessel disease included in $14.1 \%$ and $80.1 \%$, respectively (Table 2). 
Table 2. Lesion and procedural characteristics.

\begin{tabular}{|c|c|}
\hline Characteristics & Mean $\pm S D, n(\%)$ or Median $(I Q R)(n=583)$ \\
\hline \multicolumn{2}{|l|}{ ACC/AHA classification } \\
\hline Type B2/C & $59(10.1) / 480(82.4)$ \\
\hline \multicolumn{2}{|l|}{ Target vessel } \\
\hline LAD & $384(65.9)$ \\
\hline LCX & $59(10.1)$ \\
\hline RCA & $140(24.0)$ \\
\hline LM disease & $82(14.1)$ \\
\hline Multivessel disease & $467(80.1)$ \\
\hline Femoral approach & $323(55.4)$ \\
\hline \multicolumn{2}{|l|}{ Treatment type } \\
\hline POBA & $6(1.0)$ \\
\hline DEB & $17(2.9)$ \\
\hline Stent implantation & $548(94.0)$ \\
\hline Failure & $12(2.0)$ \\
\hline IVUS or OCT & $268(46.0)$ \\
\hline Escalation of Burr & $91(15.6)$ \\
\hline \multicolumn{2}{|l|}{ Maximum Burr size, $\mathrm{mm}$} \\
\hline 1.25 & $157(26.9)$ \\
\hline 1.5 & $308(52.9)$ \\
\hline 1.75 & $107(18.4)$ \\
\hline 2.0 & $10(1.7)$ \\
\hline 2.5 & $1(0.2)$ \\
\hline \multicolumn{2}{|l|}{ Access size } \\
\hline $5 \mathrm{~F}$ & $5(0.9)$ \\
\hline $6 \mathrm{~F}$ & $215(36.9)$ \\
\hline $7 \mathrm{~F}$ & $326(55.9)$ \\
\hline $8 \mathrm{~F}$ & $37(6.3)$ \\
\hline Total number of stents & $2.38 \pm 1.18$ \\
\hline Number of stents (target-vessel) & $1.66 \pm 0.68$ \\
\hline Mean stent diameter, mm (target-vessel) & $2.99 \pm 0.38$ \\
\hline Total stent length, $\mathrm{mm}$ & $69.02 \pm 35.66$ \\
\hline Stent length, mm (target-vessel) & $49.48 \pm 21.13$ \\
\hline
\end{tabular}

Values are presented as $\mathrm{n}(\%)$ or mean $\pm \mathrm{SD}$. Abbreviations: SD, standard deviation; ACC/AHA, American College of Cardiology/American Heart Association; LAD, left anterior descending; LCX, left circumflex; RCA, right coronary artery; LM, left main; POBA, plain old balloon angioplasty; DEB, drug-eluting balloon; IVUS, intravascular ultrasound; OCT, optical coherence tomography.

Detailed procedural characteristics were described in Table 2. The femoral approach was used in $55.4 \%$ of cases, whereas other cases used the radial approach. Stent implantation was performed in 548 (94.0\%) patients, plain old balloon angioplasty (POBA) in six $(1.0 \%)$, and drug-eluting balloon (DEB) in $16(2.7 \%)$. The others (11 [1.9\%] patients) could not perform anything due to technical failure. Intravascular ultrasound (IVUS) or optical coherence tomography were used in $46.0 \%$ of cases. The most frequently used burr size (maximum) was $1.5 \mathrm{~mm}(52.9 \%)$, followed by $1.25 \mathrm{~mm}, 1.75 \mathrm{~mm}, 2.0 \mathrm{~mm}$, and $2.5 \mathrm{~mm}$ $(26.9 \%, 18.4 \%, 1.7 \%$, and $0.2 \%)$.

The number of stents per patient and per lesion was $2.38 \pm 1.18$ and $1.66 \pm 0.68$. Mean stent diameter, total stent length, and stent length per lesion were $2.99 \pm 0.38,69.02 \pm 35.66$, and $49.48 \pm 21.13$, respectively. 


\section{Clinical Outcome of ROtational atherectomy in Calcified lesions in Korea} - ROCK registry -

Retrospectively Enrolled Consecutive Patients who underwent Rotational atherectomy (RA) during Percutaneous Coronary Intervention from Tertiary 9 centers in Korea between January 2010 and October 2019

542 Patients (585 Lesions) who were attempted RA were screened from each institutional database.

2 patients due to who did not use RA due to patients' condition were dropped out.

A total of 540 Patients (583 Lesions) were finally enrolled and analyzed.

Demographic and clinical characteristics, as well as procedural and follow-up clinical outcomes were collected.

The Primary endpoint : Target Vessel Failure

The Secondary endpoint : All-cause death

Cardiac death

Spontaneous myocardial infarction

Target-vessel spontaneous myocardial infarction

Any repeat revascularization

Target lesion revascularization

Target vessel revascularization

Stent thrombosis

Coronary artery bypass grafting surgery

Cerebrovascular accident

Figure 1. Study Population Flow Chart.

\subsection{Procedural Outcomes}

The rate of technical and procedural success was $96.4 \%$ and $86.1 \%$. Procedure time was 63.4 (45.0-97.0) minutes. In addition, the amount of contrast used was $210 \mathrm{~mL}$ (interquartile range [IQR)]: 150-300 mL), and the radiation dose was $2685 \mathrm{mGy}$ (IQR: 1512-4800 mGy) (Table 3).

Table 3. In-hospital Events and Procedural Outcomes.

\begin{tabular}{cc}
\hline & Mean \pm SD, $\mathbf{n}(\%)$ or Median (IQR) \\
\hline Technical success & $562(96.4)$ \\
Procedural success & $508(87.1)$ \\
Contrast amount, $\mathrm{mL}$ & $210(150-300)$ \\
Procedure time, min & $63.4(45.0-97.0)$ \\
Radiation dose, mGy & $2685(1512-4800)$ \\
In-hospital MACCEs & $62(10.6)$ \\
In-hospital death & $11(1.9)$ \\
Procedure-related myocardial infarction & $46(7.9)$ \\
Urgent revascularization & $9(1.5)$ \\
In-hospital stroke & $2(0.3)$ \\
Procedural Complications & \\
Cardiac tamponade requiring intervention & $3(0.5)$ \\
Coronary perforation & $11(1.9)$ \\
Severe coronary dissection immediate after RA & $35(6.0)$ \\
procedure * & $19(3.3)$ \\
Temporary pacemaker during RA procedure & $19(3.3)$ \\
Contrast-Induced Nephropathy & $27(4.6)$ \\
In-hospital bleeding &
\end{tabular}


As shown in Table 3, in-hospital major adverse cerebral and cardiac events (MACCEs) occurred in 62 cases $(10.6 \%)$, mainly driven by peri-procedural myocardial infarction (46 cases, 7.9\%). In-hospital death and in-hospital CVA occurred in $11(1.9 \%)$ and $2(0.3 \%)$ patients. Severe coronary dissection (Type D, E, and F) and coronary perforation occurred in $35(6.0 \%)$ and $11(1.9 \%)$ cases. Cardiac tamponade requiring intervention occurred in 3 cases $(0.5 \%)$. Urgent revascularization was needed in nine patients (1.5\%; 2 CABG; 7 PCI).

\subsection{Clinical Outcomes}

Median follow-up duration was 1.5 (IQR, 0.7-2.9) years. At 1.5 years, 72 TVFs (16.0\%) occurred and all-cause death occurred in $37(8.4 \%)$, cardiac death in $33(6.9 \%)$, spontaneous MI in $18(4.2 \%)$, target-vessel spontaneous MI in $9(2.1 \%)$, any RR in $53(12.8 \%)$, TVR in $41(9.8 \%)$, TLR in $34(8.2 \%)$, CVA in $10(2.0 \%)$, and ST in $6(1.2 \%)$ (Figure 2). One patient underwent urgent $\mathrm{CABG}$ at 11 days after the index procedure.
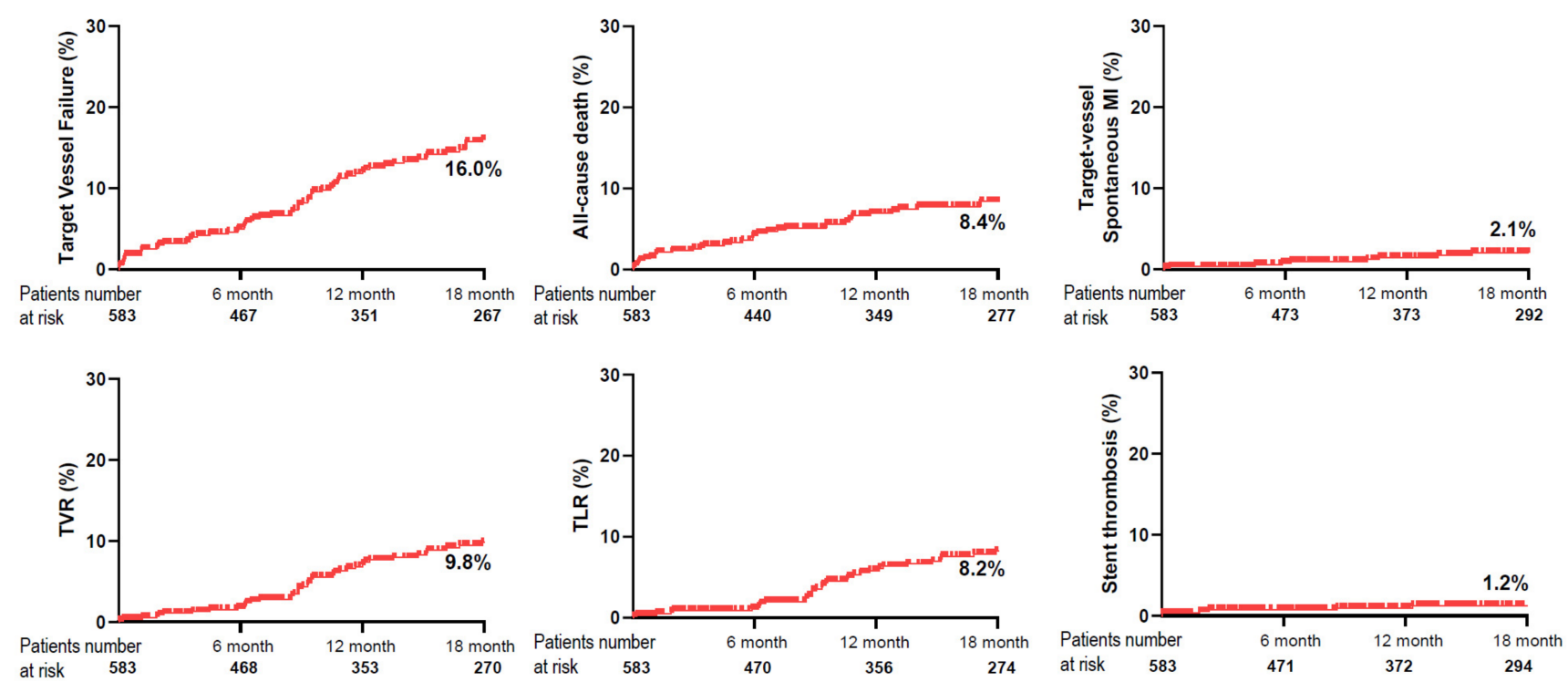

Figure 2. Kaplan-Meier Curves for Clinical Outcomes at 18 months.

We evaluated independent predictors of TVF, which included current smoker (hazard ratio $[\mathrm{HR}], 1.92 ; 95 \%$ confidence interval $(\mathrm{CI}), 1.17-3.16 ; p=0.01)$, chronic renal disease $(\mathrm{HR}, 1.87 ; 95 \% \mathrm{CI}, 1.14-3.08 ; p=0.013)$, history of cerebrovascular attack $(\mathrm{HR}, 2.14 ; 95 \% \mathrm{CI}$, $1.24-3.68 ; p=0.006)$, left ventricle ejection fraction (HR, 0.98; 95\% CI, 0.97-0.999; $p=0.037)$, and left main disease (HR, 1.94; 95\% CI, 1.11-3.37; $p=0.019)$ (Table 4). 
Table 4. Univariable and multivariable cox regression analysis of independent predictors of target-vessel failure.

\begin{tabular}{|c|c|c|c|c|}
\hline \multirow[b]{2}{*}{ Variables } & \multicolumn{2}{|c|}{ Univariate } & \multicolumn{2}{|c|}{ Multivariate * } \\
\hline & HR (95\% CI) & $p$ & HR (95\% CI) & $p$ \\
\hline Age & $0.99(0.97-1.01)$ & 0.43 & & \\
\hline Male gender & $1.12(0.74-1.70)$ & 0.59 & & \\
\hline Current smoker & $1.67(1.06-2.65)$ & 0.028 & $1.92(1.17-3.16)$ & 0.01 \\
\hline HTN & $0.97(0.60-1.57)$ & 0.91 & & \\
\hline Diabetes mellitus & $1.39(0.91-2.11)$ & 0.13 & & \\
\hline Hyperlipidemia & $0.59(0.38-0.92)$ & 0.018 & & \\
\hline Chronic kidney disease & $2.12(1.34-3.35)$ & 0.001 & $1.87(1.14-3.08)$ & 0.013 \\
\hline Family history of CAD & $1.50(0.37-6.11)$ & 0.57 & & \\
\hline Prior MI & $0.60(0.28-1.29)$ & 0.19 & & \\
\hline Prior PCI & $1.10(0.69-1.73)$ & 0.70 & & \\
\hline Prior $\mathrm{CABG}$ & $0.91(0.33-2.48)$ & 0.85 & & \\
\hline History of cerebrovascular attack & $2.15(1.32-3.50)$ & 0.002 & $2.14(1.24-3.68)$ & 0.006 \\
\hline Peripheral artery disease & $1.69(0.88-3.25)$ & 0.12 & & \\
\hline Atrial fibrillation & $1.54(0.82-2.90)$ & 0.18 & & \\
\hline LV EF (\%) & $0.98(0.96-0.99)$ & 0.003 & $0.98(0.97-0.999)$ & 0.037 \\
\hline Presented as ACS & $1.61(1.03-2.51)$ & 0.035 & $1.54(0.95-2.51)$ & 0.08 \\
\hline MVD & $0.95(0.56-1.61)$ & 0.86 & & \\
\hline LM disease & $1.68(1.02-2.75)$ & 0.041 & $1.94(1.11-3.37)$ & 0.019 \\
\hline Mean stent diameter per target vessel & $0.97(0.55-1.71)$ & 0.92 & & \\
\hline Total number of stents & $1.23(1.04-1.44)$ & 0.014 & $1.19(0.996-1.41)$ & 0.06 \\
\hline Total stent length & $1.007(1.001-1.012)$ & 0.026 & & \\
\hline
\end{tabular}

* adjusted by age, gender, current smoker, diabetes mellitus, chronic kidney disease, history of cerebrovascular attack, LV EF, presented as an acute coronary syndrome, left main disease, the total number of stents, and total stent length $\mathrm{HR}$, hazard ratio; $\mathrm{CI}$, confidence interval; HTN, hypertension; CAD, coronary artery disease; MI, myocardial infarction; PCI, percutaneous coronary intervention; CABG, coronary artery bypass grafting surgery; LV EF, left ventricle ejection fraction; ACS, acute coronary syndrome; MVD, multivessel disease; LM, left-main.

\subsection{Subgroup Analysis among Patients that Received PCI Successfully According to Clinical Presentation}

To demonstrate the high mortality rate of our registry $(27.1 \%$ during the entire followup period, 0-10.1 years), we performed a subgroup analysis of patients who received PCI successfully $(\mathrm{n}=541)$. We investigated the long-term clinical outcomes according to clinical presentation (ACS versus stable angina). Kaplan-Meier curves showed poorer clinical outcomes regarding the TVF and mortality in ACS group compared to stable angina group $(21.7 \%$ vs. $14.5 \%, \log$-rank $p=0.005 ; 14.1 \%$ vs. $6.8 \%$, log-rank $p<0.001$, respectively) (Supplement Figure S1). Multivariable cox regression analysis revealed that ACS was an independent predictor of mortality (HR, 1.94; 95\% CI, 1.002-3.75; $p=0.049$ ) (Supplement Table S3).

\section{Discussion}

Major findings from our study were as follows: (1) Technical and procedural success rate of RA was acceptable in heavily calcified and diffuse coronary lesions; (2) RA during PCI was safe and efficient for revascularization regarding in-hospital MACCEs and procedural complications, as well as procedural outcomes (procedure time, contrast amount, or radiation dose); (3) the independent predictors of TVF were identified from our registry.

This 'ROtational atherectomy in Calcified lesions in Korea (ROCK)' registry is the largest, all-comer, multi-center registry, including patients undergoing RA in Korea. Patients who were received PCI were implanted with drug-eluting stents (DESs), especially 2nd generation DES, except for one patient with 1st generation DES, which might reflect the clinical outcomes of RA in the 2nd-generation DES era. As described previously, DAPT and statin were prescribed above $90 \%$ of the study population, which would reflect that these patients were treated as current guidelines $[14,17,18]$. 
All cases except for a few chronic total occlusion or in-stent restenosis cases were calcified and diffuse disease, represented by $82.4 \%$ of lesions classified as type C (ACC/AHA classification). In $38 \%$ of cases, RA was done due to unsuccessful $2.0 \mathrm{~mm}$ sized or bigger balloon predilatation. In the others, RA was done promptly based on the operator's decision. It was based on angiographic findings, the calcification arc revealed by intravascular images, the friction of smaller balloons or wires, etc. Although, we provided data of acceptable efficacy outcomes regarding success rate and procedural outcomes. We achieved final TIMI 3 in $96.4 \%$ of all cases, similar to the previous studies [1,12,19-21]. The absolute values of procedure time and contrast amount were smaller compared to the previous study [20].

The study population consisted of patients with advanced coronary atherosclerosis and high comorbidity. Indeed, diabetes mellitus accounted for more than half of the study population, and more than $80 \%$ were multivessel diseases. From the current guideline, for revascularization of multivessel disease accompanied by diabetes, we should consider CABG [22,23]. However, because of high-risk peri-operative mortality and morbidity and patients' preference, operators chose the PCI with RA instead of CABG for those patients in this registry. Although, in-hospital MACCEs and procedural complications showed feasible and acceptable results compared to other previous studies [1,12,19-21]. However, in-hospital MACCEs were developed in $10.6 \%$ of our registry, mainly driven by peri-procedural MI, which showed higher events than previous studies. We thought plausible explanations as follows; (1) because we included more than $60 \%$ of ACS patients; (2) events were recorded according to 10 times elevation of the cardiac enzyme (CK-MB) with medical records, would be over-estimated. Coronary perforation occurred in $1.9 \%$ of cases, consistent with previous studies (0.5-2.3\%) [12,19-21].

As shown in Table 5, our study showed relatively high mortality similar to that of the J2T Multicenter registry [1]. We found one possible explanation from baseline clinical demographics in both of the two studies, which might be due to a large proportion (more than $50 \%$ ) of the acute coronary syndrome (ACS). Our subgroup analysis demonstrated ACS was an independent predictor of mortality among patients who received PCI successfully.

Table 5. Comparison with previous studies of rotational atherectomy including technical success and follow-up clinical outcomes.

\begin{tabular}{|c|c|c|c|c|c|c|c|c|c|}
\hline & $\begin{array}{l}\text { All Study } \\
\text { Popula- } \\
\text { tion }\end{array}$ & Era & $\begin{array}{c}\text { Technical } \\
\text { Success, } \\
\%\end{array}$ & $\begin{array}{c}\text { Follow-Up } \\
\text { Duration }\end{array}$ & $\begin{array}{c}\text { All- } \\
\text { Cause } \\
\text { Death, \% }\end{array}$ & $\begin{array}{c}\text { TVR, } \\
\%\end{array}$ & $\begin{array}{c}\text { TLR, } \\
\%\end{array}$ & $\begin{array}{l}\text { ST, } \\
\%\end{array}$ & $\underset{\%}{\text { CVA, }}$ \\
\hline Okai et al. [1] & 1090 & DES & 96.2 & $\begin{array}{c}3.8 \text { (IQR 1.9-6.1) } \\
\text { years }\end{array}$ & 24.2 & 21.4 & 16.2 & 1.3 & 4.7 \\
\hline $\begin{array}{c}\text { Kawamoto } \\
\text { et al. [20] }\end{array}$ & 985 & $\begin{array}{c}8.8 \% \\
\text { BMS91.2\% } \\
\text { DES }\end{array}$ & 99.1 & 2 years & 9.5 & 19.8 & 16.6 & 1.8 & 1.0 \\
\hline $\begin{array}{c}\text { Cortese et al. } \\
{[21]}\end{array}$ & 1397 & $\begin{array}{c}17 \% \\
\text { POBA } 40.7 \% \\
\text { BMS42\% DES }\end{array}$ & 99.3 & $2.4(0.8-5.7)$ years & 6.4 & - & 11.7 & 1.4 & - \\
\hline $\begin{array}{c}\text { Rathore et al. } \\
\text { [19] }\end{array}$ & 516 & $\begin{array}{c}24.2 \% \\
\text { BMS75.8\% } \\
\text { DES }\end{array}$ & 99.4 & 6-9 months & - & - & 14.4 & $0.8^{*}$ & - \\
\hline $\begin{array}{l}\text { Abdel-Wahab } \\
\text { et al. [12] }\end{array}$ & 205 & DES & 98.0 & $1.3(0.08-7)$ years & 9.0 & 11.2 & 7.9 & 1.0 & - \\
\hline Our study ${ }^{* *}$ & 540 & DES & 96.4 & $\begin{array}{c}1.5 \text { (IQR 0.7-2.9) } \\
\text { years }\end{array}$ & 8.4 & 9.8 & 8.2 & 1.2 & 2.0 \\
\hline
\end{tabular}

* Includes only late stent thrombosis. ${ }^{* *}$ Event rates at 18 months were estimated on Kaplan-Meier estimates in time-to-first-event analyses. TVR, target-vessel revascularization; TLR, target-lesion revascularization; ST, stent thrombosis; CVA, cerebrovascular accident; DES, drug-eluting stent; IQR, interquartile range; BMS, bare metal stent; POBA, plain old balloon angioplasty.

Patients received 2nd-generation DES were included in 36.3\% (J2T Multicenter registry) [1] and $69.3 \%$ (ROTATE registry) [20]. In our registry, as mentioned above, we included $99.8 \%$ of 2 nd-generation DES among patients treated with stent implantation. 
This homogeneity of implanted stents is the unique and valuable strength of our registry. Moreover, nearly half of the cases were performed procedures with intravascular image guidance. We could evaluate the benefit of intravascular guidance in RA with our data.

TVF occurred in $16.0 \%$ at 1.5 years, which showed acceptable clinical outcomes to previous studies considering that our study population consisted of more elderly patients, ACS patients, including ST-elevation MI, and the long-term follow-up period. We summarized clinical outcomes compared with previous studies of RA (Table 5).

\section{Limitation}

Our study has several limitations. This was a non-randomized, observational, singlearm, retrospective study. Due to the relatively large number of centers included in the study over the long study period, there may be confounders that have not been accounted for. Second, the registry included a relatively limited number of patients and insufficient follow-up duration to evaluate the long-term clinical outcomes. Third, parameters of lesion complexity (such as SYNTAX score or quantitative coronary angiography) were not available. Therefore, our findings should be further evaluated after reassessing those parameters.

\section{Conclusions}

Our study has provided a large registry for in-hospital and long-term clinical outcomes of RA in the 2nd-generation DES era, which showed acceptable success rates, in-hospital, and long-term clinical outcomes.

Supplementary Materials: The following are available online at https:/ /www.mdpi.com/article/10 .3390/medicina57070694/s1, Figure S1: Kaplan-Meier curves for 3-year clinical outcomes according to clinical presentation., Table S1: Clinical characteristics according to clinical presentation among patients received PCI successfully., Table S2: Lesion and procedural characteristics according to clinical presentation among patients received PCI successfully., Table S3: Multivariable Cox Regression Analysis of Independent Predictors of all-cause death.

Author Contributions: K.L. designed the study, collected data, analyzed the data, drafted and revised the manuscript, drew figures; J.-h.J., M.L., D.-W.K., M.-W.P., I.-J.C., J.-H.L. (Jae-Hwan Lee), J.H.L. (Jang-Hoon Lee), S.-R.L., P.-H.L., S.-W.L., K.-D.Y., K.-H.Y., and H.-J.L. (Jang-Hoon Lee) collected data; S.-H.H. designed the study, collected data, validated data, and revised the manuscript. All authors have read and agreed to the published version of the manuscript.

Funding: This work was supported by grants from the Nuri Cardiovascular Society Foundation of South Korea.

Institutional Review Board Statement: The study was conducted according to the guidelines of the Declaration of Helsinki, and approved by the Institutional Review Board of Daejeon St. Mary's Hospital (DC19REDI0066 and 30 July 2019).

Informed Consent Statement: Patient consent was waived due to retrospective design of this study.

Data Availability Statement: The data presented in this study are available on request from the corresponding author.

Conflicts of Interest: The authors declare no conflict of interest.

\section{References}

1. Characteristics and Long-Term Outcomes of Rotational Atherectomy-J2T Multicenter Registry. Circ. J. Off. J. Jpn. Circ. Soc. 2018, 82, 369-375. [CrossRef]

2. Hill, J.M.; Kereiakes, D.J.; Shlofmitz, R.A.; Klein, A.J.; Riley, R.F.; Price, M.J.; Herrmann, H.C.; Bachinsky, W.; Waksman, R.; Stone, G.W. Intravascular Lithotripsy for Treatment of Severely Calcified Coronary Artery Disease. J. Am. Coll. Cardiol. 2020, 76, 2635-2646. [CrossRef] [PubMed]

3. Barbato, E.; Carrié, D.; Dardas, P.; Fajadet, J.; Gaul, G.; Haude, M.; Khashaba, A.; Koch, K.; Meyer-Gessner, M.; Palazuelos, J.; et al. European expert consensus on rotational atherectomy. EuroIntervention 2015, 11, 30-36. [CrossRef] [PubMed]

4. Lee, M.S.; Gordin, J.S.; Stone, G.W.; Sharma, S.K.; Saito, S.; Mahmud, E.; Chambers, J.; Généreux, P.; Shlofmitz, R. Orbital and rotational atherectomy during percutaneous coronary intervention for coronary artery calcification. Catheter. Cardiovasc. Interv. 2018, 92, 61-67. [CrossRef] 
5. De Maria, G.L.; Scarsini, R.; Banning, A.P. Management of Calcific Coronary Artery Lesions: Is it Time to Change Our Interventional Therapeutic Approach? JACC Cardiovasc. Interv. 2019, 12, 1465-1478. [CrossRef] [PubMed]

6. Ahn, S.S.; Auth, D.; Marcus, D.R.; Moore, W.S. Removal of focal atheromatous lesions by angioscopically guided high-speed rotary atherectomy: Preliminary experimental observations. J. Vasc. Surg. 1988, 7, 292-300. [CrossRef]

7. Tomey, M.I.; Kini, A.S.; Sharma, S.K. Current status of rotational atherectomy. JACC Cardiovasc. Interv. 2014, 7, 345-353. [CrossRef] [PubMed]

8. Tamekiyo, H.; Hayashi, Y.; Toyofuku, M.; Ueda, H.; Sakuma, T.; Okimoto, T.; Otsuka, M.; Imazu, M.; Kihara, Y. Clinical outcomes of sirolimus-eluting stenting after rotational atherectomy. Circ. J. Off. J. Jpn. Circ. Soc. 2009, 73, 2042-2049. [CrossRef]

9. Mezilis, N.; Dardas, P.; Ninios, V.; Tsikaderis, D. Rotablation in the drug eluting era: Immediate and long-term results from a single center experience. J. Interv. Cardiol. 2010, 23, 249-253. [CrossRef] [PubMed]

10. Jinnouchi, H.; Kuramitsu, S.; Shinozaki, T.; Kobayashi, Y.; Hiromasa, T.; Morinaga, T.; Mazaki, T.; Sakakura, K.; Soga, Y.; Hyodo, M.; et al. Two-Year Clinical Outcomes of Newer-Generation Drug-Eluting Stent Implantation Following Rotational Atherectomy for Heavily Calcified Lesions. Circ. J. Off. J. Jpn. Circ. Soc. 2015, 79, 1938-1943. [CrossRef]

11. Benezet, J.; Díaz de la Llera, L.S.; Cubero, J.M.; Villa, M.; Fernández-Quero, M.; Sánchez-González, A. Drug-eluting stents following rotational atherectomy for heavily calcified coronary lesions: Long-term clinical outcomes. J. Invasive Cardiol. 2011, 23, 28-32.

12. Abdel-Wahab, M.; Baev, R.; Dieker, P.; Kassner, G.; Khattab, A.A.; Toelg, R.; Sulimov, D.; Geist, V.; Richardt, G. Long-term clinical outcome of rotational atherectomy followed by drug-eluting stent implantation in complex calcified coronary lesions. Catheter. Cardiovasc. Interv. 2013, 81, 285-291. [CrossRef] [PubMed]

13. Matsuo, S.; Imai, E.; Horio, M.; Yasuda, Y.; Tomita, K.; Nitta, K.; Yamagata, K.; Tomino, Y.; Yokoyama, H.; Hishida, A. Revised equations for estimated GFR from serum creatinine in Japan. Am. J. kidney Dis. Off. J. Natl. Kidney Found. 2009, 53, 982-992. [CrossRef] [PubMed]

14. Levine, G.N.; Bates, E.R.; Bittl, J.A.; Brindis, R.G.; Fihn, S.D.; Fleisher, L.A.; Granger, C.B.; Lange, R.A.; Mack, M.J.; Mauri, L.; et al. 2016 ACC/AHA Guideline Focused Update on Duration of Dual Antiplatelet Therapy in Patients With Coronary Artery Disease: A Report of the American College of Cardiology/American Heart Association Task Force on Clinical Practice Guidelines: An Update of the 2011 ACCF/AHA/SCAI Guideline for Percutaneous Coronary Intervention, 2011 ACCF/AHA Guideline for Coronary Artery Bypass Graft Surgery, 2012 ACC/AHA/ACP/AATS/PCNA/SCAI/STS Guideline for the Diagnosis and Management of Patients With Stable Ischemic Heart Disease, 2013 ACCF/AHA Guideline for the Management of ST-Elevation Myocardial Infarction, 2014 AHA/ACC Guideline for the Management of Patients With Non-ST-Elevation Acute Coronary Syndromes, and 2014 ACC/AHA Guideline on Perioperative Cardiovascular Evaluation and Management of Patients Undergoing Noncardiac Surgery. Circulation 2016, 134, e123-e155. [CrossRef]

15. Levine, G.N.; Bates, E.R.; Blankenship, J.C.; Bailey, S.R.; Bittl, J.A.; Cercek, B.; Chambers, C.E.; Ellis, S.G.; Guyton, R.A.; Hollenberg, S.M.; et al. 2011 ACCF/AHA/SCAI guideline for percutaneous coronary intervention: A report of the American College of Cardiology Foundation/American Heart Association Task Force on Practice Guidelines and the Society for Cardiovascular Angiography and Interventions. Catheter. Cardiovasc. Interv. 2013, 82, E266-E355. [CrossRef] [PubMed]

16. Moussa, I.D.; Klein, L.W.; Shah, B.; Mehran, R.; Mack, M.J.; Brilakis, E.S.; Reilly, J.P.; Zoghbi, G.; Holper, E.; Stone, G.W. Consideration of a new definition of clinically relevant myocardial infarction after coronary revascularization: An expert consensus document from the Society for Cardiovascular Angiography and Interventions (SCAI). J. Am. Coll. Cardiol. 2013, 62, 1563-1570. [CrossRef]

17. 2019 ESC/EAS guidelines for the management of dyslipidaemias: Lipid modification to reduce cardiovascular risk. Atherosclerosis 2019, 290, 140-205. [CrossRef]

18. Grundy, S.M.; Stone, N.J.; Bailey, A.L.; Beam, C.; Birtcher, K.K.; Blumenthal, R.S.; Braun, L.T.; de Ferranti, S.; Faiella-Tommasino, J.; Forman, D.E.; et al. 2018 AHA/ACC/AACVPR/AAPA/ABC/ACPM/ADA/AGS/APhA/ASPC/NLA/PCNA Guideline on the Management of Blood Cholesterol: A Report of the American College of Cardiology/American Heart Association Task Force on Clinical Practice Guidelines. Circulation 2019, 139, e1082-e1143. [CrossRef]

19. Rathore, S.; Matsuo, H.; Terashima, M.; Kinoshita, Y.; Kimura, M.; Tsuchikane, E.; Nasu, K.; Ehara, M.; Asakura, Y.; Katoh, O.; et al. Rotational atherectomy for fibro-calcific coronary artery disease in drug eluting stent era: Procedural outcomes and angiographic follow-up results. Catheter. Cardiovasc. Interv. 2010, 75, 919-927. [CrossRef]

20. Kawamoto, H.; Latib, A.; Ruparelia, N.; Ielasi, A.; D’Ascenzo, F.; Pennacchi, M.; Sardella, G.; Garbo, R.; Meliga, E.; Moretti, C.; et al. In-hospital and midterm clinical outcomes of rotational atherectomy followed by stent implantation: The ROTATE multicentre registry. EuroIntervention 2016, 12, 1448-1456. [CrossRef]

21. Cortese, B.; Aranzulla, T.C.; Godino, C.; Chizzola, G.; Zavalloni, D.; Tavasci, E.; De Benedictis, M.; Ettori, F.; Presbitero, P.; Colombo, A. Drug-eluting stent use after coronary atherectomy: Results from a multicentre experience-The ROTALINK I study. J. Cardiovasc. Med. 2016, 17, 665-672. [CrossRef] [PubMed] 
22. Patel, M.R.; Calhoon, J.H.; Dehmer, G.J.; Grantham, J.A.; Maddox, T.M.; Maron, D.J.; Smith, P.K. ACC/AATS/AHA/ASE/ASNC/ SCAI/SCCT/STS 2017 Appropriate Use Criteria for Coronary Revascularization in Patients With Stable Ischemic Heart Disease: A Report of the American College of Cardiology Appropriate Use Criteria Task Force, American Association for Thoracic Surgery, American Heart Association, American Society of Echocardiography, American Society of Nuclear Cardiology, Society for Cardiovascular Angiography and Interventions, Society of Cardiovascular Computed Tomography, and Society of Thoracic Surgeons. J. Am. Coll. Cardiol. 2017, 69, 2212-2241. [CrossRef] [PubMed]

23. Roffi, M.; Patrono, C.; Collet, J.P.; Mueller, C.; Valgimigli, M.; Andreotti, F.; Bax, J.J.; Borger, M.A.; Brotons, C.; Chew, D.P.; et al. 2015 ESC Guidelines for the management of acute coronary syndromes in patients presenting without persistent ST-segment elevation: Task Force for the Management of Acute Coronary Syndromes in Patients Presenting without Persistent ST-Segment Elevation of the European Society of Cardiology (ESC). Eur. Heart J. 2016, 37, 267-315. [CrossRef] [PubMed] 